\title{
Family Medicine and
Community Health Enhancing your scholarship as a family medicine junior faculty member
}

\author{
Lisa K Rollins
}

To cite: Rollins LK. Enhancing your scholarship as a family medicine junior faculty member. Fam Med Com Health 2020;8:e000426. doi:10.1136/ fmch-2020-000426

Check for updates

(c) Author(s) (or their employer(s)) 2020. Re-use permitted under CC BY-NC. No commercial re-use. See rights and permissions. Published by BMJ.

Department of Family Medicine, University of Virginia Charlottesville, Virginia, USA

Correspondence to Dr Lisa K Rollins; Ikr2h@virginia.edu

\begin{abstract}
Family medicine faculty are often expected to produce some form of scholarship as members of academic departments. However, this can be challenging given a range of contextual factors, including limited research capacity in many departments, increased competition for funding and individual challenges around balancing multiple roles, unclear expectations and lack of mentorship, to name a few. The purpose of this reflection is to discuss seven content areas that might be addressed by faculty in order to promote scholarship, particularly among junior faculty. These include: 1) knowing your academic track and its associated expectations by rank, as well as the scholarship expectations within your department; 2) considering your personal goals, interests, professional development needs and the relationship between meaningful work and burnout; 3) starting small and building towards a niche content area; 4) finding collaborators and the benefits of collaboration; 5) seeking alignment between your scholarship and work that you already are performing; 6) educating yourself about available outlets for scholarship and 7) seeking mentorship.
\end{abstract}

Academic departments of family medicine provide opportunities for faculty to pursue multiple professional interests, including clinical care, teaching and research. While the research and scholarship capacity in family medicine is growing, this capacity remains limited, ${ }^{1}$ and in 2019 , departments of family medicine received only $5 \%$ of National Institutes of Health funding to all medical school departments. ${ }^{2}$ A number of reasons have been proposed for this limited funding, including: lower perceived value of primary care research; the challenges of conducting community-based research; increased competition for limited funds and challenges in finding family medicine research mentors, among others. ${ }^{3}$ However, even within the presence of this challenging context, academic family physicians are often expected to conduct scholarly activities. For the sake of this reflection, scholarship will be considered broadly, as described by Boyer, and includes ${ }^{4}$ :
- Scholarship of discovery (original research);

- Scholarship of integration (synthesising information across disciplines);

- Scholarship of application (applying existing information in new ways);

- Scholarship of teaching (studying teaching and learning; creating educational content that is peer reviewed and placed in the public domain).

The Accreditation Council of Graduate Medical Education has issued guidelines for faculty scholarly activity, where programmes must demonstrate accomplishments in at least three of the following domains (p.33):

- Research in basic science, education, translational science, patient care or population health;

- Peer-reviewed grants;

- Quality improvement and/or patient safety initiatives;

- Systematic reviews, meta-analyses, review articles, chapters in medical textbooks or case reports;

- Creation of curricula, evaluation tools, didactic educational activities or electronic educational materials;

- Contribution to professional committees, educational organisations or editorial board;

- Innovations in education. ${ }^{5}$

In addition, even if an individual is hired within a non-tenure clinician educator track, there may be some expectation for personal scholarship, depending on the institution.

Family medicine is poised to provide significant scholarly contributions as it serves as a conduit connecting the care of communities, population health and the care of individual patients. ${ }^{3}$ The specialty of family medicine is also pivotal to providing foundational clinical knowledge to medical students. Yet, there are often significant challenges to faculty engaging in scholarship at an individual level, particularly among junior faculty. Junior faculty may find it particularly difficult to balance their multiple roles; scholarship expectations may not be made clear to them; they may find it difficult to find good 
mentors; more senior faculty may focus junior faculty efforts on an excessive number of tasks and/or low level tasks that will not be useful for promotion and junior faculty may lack a sense of perseverance and/or an associated understanding of the context around publishing and grant submissions and the rejection process. ${ }^{6}$ Work-home conflicts are particularly prevalent among early and midcareer physicians. ${ }^{7}$ In addition, family medicine faculty indicate that they have limited time, minimal mentorship and they need to improve their writing skills. ${ }^{8}$

The purpose of this reflection is to highlight seven components and educational content areas that I have found useful in trying to facilitate scholarship among family medicine faculty, particularly junior level faculty. My perspective comes from my role as Director of our Family Medicine Faculty Development Fellowship for the past 6 years. I also teach our fellowship course on Professional Development and Socialisation and I frequently consult with faculty pertaining to grant writing, manuscripts, survey design and other scholarly endeavours. The areas described are at the individual level and do not address the larger contextual issues pertaining to family medicine departments and their academic infrastructure.

1) Know your academic track and the institutional expectations for this track according to your rank (assistant, associate or full professor): I have been somewhat surprised at the number of junior faculty who are not sure about their track or are confused about the difference between track and rank. It is critical for you to know your track (eg, clinician educator) and whether you are tenure track or non-tenure track, as the scholarship expectations will be significantly different. The names of tracks may vary slightly across institutions, as may the scholarship expectations, so it is important to understand your institution's expectations. In addition, most academic departments have some form of annual review for individual faculty and it is important for you to discuss scholarship expectations at these reviews. Specifically, as a faculty member it is vital to understand both the institutional and departmental expectations for your scholarship output.

2) Consider your goals, interests and professional development needs: what content areas are of interest to you? Are you interested in improving how you practice? If so, you may be interested in quality improvement initiatives. Are you interested in teaching? If so, you may be interested in exploring the best ways to teach your medical students or residents. Are you interested in health disparities? If so, you may be interested in pursuing activities around health policy, advocacy or clinical research. Are you interested in evidence-based care? If so, you may be interested in conducting evidence-based reviews around specific clinical content areas. The opportunities are almost endless. I have often found that family physicians are true generalists and they are interested in many areas. While being excited about multiple content areas can be a good thing, it also can create problems because faculty may have trouble focusing or choosing an area to pursue. However, it is important to define the work that is meaningful to you yet also aligns with your department and your institution. According to a survey in 2017, approximately $44 \%$ of family physicians experienced at least one symptom of burnout as measured by the Maslach Burnout Inventory. ${ }^{9}$ Yet, participating in work that has personal meaning has a strong inverse relationship to burnout ${ }^{10}$ and is a known buffer. ${ }^{11}$ A variety of approaches can help faculty define meaningful work, including reflecting on personal and family goals; creating a brief end-of-career autobiography; values clarification exercises, including defining ones values, passions and strengths and journaling exercises, to name a few. ${ }^{12}$ There are many paths one can take when developing a career. Take some time to identify your interests and explore them early, with an eye towards developing an eventual area of focus.

In addition to identifying your goals and interests, it also is important to consider what professional development will be needed in order for you to succeed. The opportunities are wide ranging and can include conference or workshop sessions, certificate programmes, fellowships through either institutions or professional organisations (eg, fellowships in faculty development, research and medical editing), Master's programmes in education or public health, mentored grants (eg, K Award), as well as other professional training available through your institution and professional organisations.

3) Start small: I have found that some junior faculty may suffer from a sense of paralysis as they embark on the beginning of their academic career. They are seeking that 'big' grant or a project that will set them apart and they may either have difficulty finding that 'perfect' project or they may be seeking something that is beyond their level of experience and/or expertise. As a result, nothing or very little happens. While it may be possible to 'hit it big' the first time out, this is usually rare. Early in a career, it sometimes can be more helpful to start with smaller projects where the likelihood for success is greater. For example, small grants from local agencies, pilot funds from your own institution, small projects in your area of interest or joining an existing project that is directed by a more senior faculty member. These options enable you to begin to establish your reputation or niche in an area and gives you a form of academic leverage and new found knowledge as you move to bigger projects. You may try some different things before you settle on something, but the important thing is to start.

4) Find collaborators: it can be daunting to generate scholarship from scratch, particularly if you are trying to do it on your own. As a result, consider opportunities to join more senior level faculty members early in your academic career, whether through involvement in their research or as part of a writing team for an article. In addition, collaborators can help you with multiple tasks. For example, can you use your reference librarian to assist in your literature review? Are there individuals available at your institution who can assist you with necessary analyses? Are there individuals within your department, across departments, across the institution or at other institutions 
with whom you share specific interests? Collaborations are often a key element to scholarship success and they can serve a number of functions: they can be intellectually stimulating, they can give you important access to content expertise, they can enhance rigour and fundability of projects, they can create mutual accountability, they can provide a mechanism to divvy up the workload and they often can enable individuals to work towards their strengths.

5) Seek scholarship while conserving energy: while this may seem contradictory at first glance, it actually is possible to pursue scholarship while conserving energy. Over the years, I have heard multiple junior faculty say, "I just cannot take on anything new". However, if one considers the concept of alignment and the typically noted barrier of time, it is possible to come to an easy conclusion to pursue scholarship pertaining to work you already are doing or plan to do. For example, if you are involved with a quality improvement initiative related to your patientcentred medical home activities within your practice, design the initiative in a manner that might enable it to be published once completed. If you are seeking to improve your residency, design your predata and postdata gathering and implementation activities in a manner that will facilitate publication. If you are developing a new curriculum, create the materials in a manner that enables you to upload them to a peer-reviewed digital resource library. If you created a strong professional conference presentation, convert it into a publication. ${ }^{13}$

Thinking about design issues for future scholarship requires forethought, but it can save you significant time on the back end. While it indeed will take some time to write up your results, it will take far less time if you have already collected all of the information that you will need. There are many resources available to provide guidance regarding how to design activities with an eye towards rigour and publication. The following is a preliminary list that is by no means exhaustive:

Quality improvement: Squire V.2.0 provides a helpful guideline that outlines areas to be described in detail for publication when conducting quality improvement initiatives. ${ }^{14}$ The Institute for Healthcare Improvement (http://www.IHI.org) also offers a variety of in-person and virtual training opportunities.

Research: if you are planning to design a research project, whether related to clinical care or teaching, the criteria by Glassick et al can provide a useful stepped approach. ${ }^{15}$ There are many resources pertaining to research design and methodology, including textbooks, ${ }^{16}$ journal articles, courses and guidelines. In addition, the EQUATOR Network (https://www.equator-network.org/toolkits/) provides helpful toolkits pertaining to research.

Educational evaluation: Kirkpatrick's model is useful to consider as you are designing your educational activity and its associated assessment. ${ }^{17}$

Survey research: if you are planning to develop and implement a survey, this editorial in the journal Academic Medicine provides a useful summary of the important components to include when submitting your work for publication. ${ }^{18}$

Evidence-based reviews: if you are interested in writing an evidence-based review, this article by Siwek et al provides a helpful framework for you to follow. ${ }^{19}$ A variety of evidence-based resources are available including Cochrane, DynaMed Plus and Up-To-Date, among others. Additionally, articles are available through resources such as OVID and PubMed. Just be sure to keep track of your search strategy, as this will need to be described in your review.

There are many other resources as well so be sure to seek out resources and any needed training ahead of time that will be relevant to your proposed activity. The more effectively you plan upfront, the easier it will be to generate scholarship when your project is completed.

6) Educate yourself about available avenues for your scholarship: there are many scholarship outlets that you can pursue for your work:

Professional conferences: professional conferences are often a great first-line outlet for scholarship. Professional organisations typically provide helpful information on their websites for those who are submitting, including descriptions of the various formats, sample submissions, frequently asked questions, etc. In addition, consider whether you can seek a second scholarship opportunity by submitting a paper to a journal, post-conference, pertaining to the conference presentation.

Professional journals: there are a host of available journals where family medicine-related scholarship might be published, including journals pertaining to family medicine, ${ }^{13}$ general internal medicine, medical education, population health, rural health, practice management, sports medicine, information technology, etc. For example, Journal Citation Reports (JCR) currently indexes 19 journals within the category 'Primary Healthcare', 41 journals in 'Education, Scientific Disciplines' and 160 journals under the category of 'Medicine, General and Internal'. ${ }^{20}$ While the impact factors and the publication requirements vary for each journal, it can be helpful to peruse the JCR for potential relevant journals as a starting point to identify where you would like to

Table 1

\begin{tabular}{|c|c|c|}
\hline Example formats & & \\
\hline Journal 1 & Journal 2 & \\
\hline Clinical Review & Original Research & Essays \\
\hline Curbside Consult & Methodology & $\begin{array}{l}\text { Innovations in } \\
\text { Primary Care }\end{array}$ \\
\hline $\begin{array}{l}\text { Diary from a Week in } \\
\text { Practice }\end{array}$ & Theory & \\
\hline Editorials & $\begin{array}{l}\text { Systematic } \\
\text { Reviews }\end{array}$ & \\
\hline Letters to the Editor & Research Briefs & \\
\hline Photo Quiz & Special Reports & \\
\hline
\end{tabular}


submit. I also have found it helpful to identify the journals in which I found relevant articles for the literature review, as this too can provide insight into the journals that would be interested in your manuscript content area. As an overall review, Gottlieb et al provide a useful introduction to writing and publishing for junior faculty. ${ }^{21}$

It is important to consider the journal and format prior to writing so you are able to generate your submission in the appropriate format while meeting the required word count. This information can usually be found in an Information for Authors section on the journal's respective website. There are many available formats for journal submissions. Examples from just two primary care journals are found in table 1. It can be helpful to review multiple relevant journals to identify a journal and format that is well suited to your content. There are many options so keep looking if you do not find an appropriate format in the first journal you are considering. In addition, consider perusing a few copies of the journal that you are considering prior to writing. This can help you determine if your article will fit conceptually with their typical content and format before going through the effort of submission.

In addition, when selecting a journal, particularly in reference to promotion and tenure, consider the journal's impact factor, although be wary of predatory journals. Typically, journals with higher impact factors are likely to be viewed more favourably by promotion committees, although this should not be the only factor that you consider.

Online data portals: if you have developed curricula or conducted medical education research, you might consider submitting to an online data portal, for example, MedEdPortal (https://www.mededportal.org/) through the Association of American Medical Colleges or Peer-eviewed Reports in Medical Education Research (https://journals.stfm.org/primer) through the Society of Teachers of Family Medicine. Many of these data portals incorporate a peer-reviewed option and use a ticking system that tracks the number of times your uploaded information has been downloaded by a user. This ticker data can be incorporated into your curriculum vitae at the time of promotion to reflect frequency of use and indirectly, to reflect potential impact.

Grants: a separate article could easily be written about grants. Nevertheless, at the federal level, there are multiple grant opportunities through the National Institutes of
Health depending on the scale of your project. These include, but are not limited to:

- RO1-large-scale research project, usually 3-5 years;

- R03-small-scale research, maximum 2 years, up to 50 $\mathrm{k}$;

- R21-exploratory, maximum 2 years, up to $275 \mathrm{k}$, no prelim data;

- R41/42—small business technology transfer (STTR);

- R43/44-small business innovative research;

- P Series-programme project/centre grants;

- K Awards-career development.

In addition, there are other possible sources of funding at both the national and local level, including:

National:

- Other federal agencies;

- Foundations;

- National professional organisations;

- Other national organisations.

Regional/Local (these will be very specific to your area):

- Local foundations;

- Local businesses and places of worship;

- Your institution.

7) Seek mentorship: as previously noted, it may be challenging to find a family medicine faculty member who is able to serve as an effective scholarship mentor. However, multilevel mentorship enhances scholarly productivity and skills. ${ }^{22}$ Be sure to think broadly about your mentorship needs and consider whether you may need multiple mentors. For example, one mentor may help you negotiate career decisions over time. Another mentor may help open doors for you or provide important professional contacts. Yet another mentor may provide expertise within a certain content area of need. In addition, as with the collaborators, you may need to seek mentor(s) within your department, your home institution or at another institution or beyond. You also may need to be proactive in this process if your institution does not have an active mentoring programme already established. For example, the Grant Generating Project may be particularly helpful if you are new to grant writing and would like to build these skills under the mentorship of experienced grant writers. (https://www.stfm.org/publicationsresearch/ otherresearchresources/grantgeneratingproject/).

It can be challenging to balance scholarship productivity with the multiple demands typically placed on

Table 2 Scholarship examples

\begin{tabular}{ll}
\hline Scholarship & Examples \\
\hline Discovery & Publishing original research, grants. \\
Integration & Evidence-based reviews, meta-analyses, book chapters, review articles, commentaries. \\
Application & $\begin{array}{l}\text { Quality improvement projects, assessing different approaches to healthcare delivery, assessing clinical } \\
\text { guidelines, case studies. }\end{array}$ \\
Teaching & $\begin{array}{l}\text { Assessing the efficacy or effectiveness of different instructional approaches, uploading curricula to } \\
\text { educational database portals, conference presentations/posters pertaining to educational programmes. }\end{array}$ \\
\hline
\end{tabular}


academic family physicians. However, it most certainly is possible to be productive, particularly if you educate yourself; seek collaborations; pursue areas that are important to you; maintain alignment of your goals, academic interests and professional activities; review work you are doing with an eye towards scholarship and seek mentorship. To stimulate your thinking, a few examples for each of Boyer's scholarship areas are found in table 2.

Maintaining a sense of professional inquiry can be exciting, energising and infectious to your peers, residents and students. The specialty of family medicine has much to offer in terms of scholarly contributions to enhance the society in which we live. Perhaps this reflection will provide some insights to help you enhance your personal scholarship as you develop your career as an academic family physician.

Contributors I am the sole author and have conducted all of the planning and writing of this work. I was responsible for the conceptualisation, editing and final approval. I also am corresponding author and therefore accountable and will ensure that any questions are addressed and resolved.

Funding The authors have not declared a specific grant for this research from any funding agency in the public, commercial or not-for-profit sectors.

Competing interests None declared.

Patient consent for publication Not required.

Provenance and peer review Not commissioned; externally peer reviewed.

Open access This is an open access article distributed in accordance with the Creative Commons Attribution Non Commercial (CC BY-NC 4.0) license, which permits others to distribute, remix, adapt, build upon this work non-commercially, and license their derivative works on different terms, provided the original work is properly cited, appropriate credit is given, any changes made indicated, and the use is non-commercial. See: http://creativecommons.org/licenses/by-nc/4.0/.

\section{REFERENCES}

1 Ewigman B, Davis A, Vansaghi T, et al. Building research \& scholarship capacity in departments of family medicine: A new joint adfm-napcrg initiative. Ann Fam Med 2016;14:82-3.

2 Blue ridge Institute for medical research. Available: www.https:// BRIMR.org/NIH_Awards/2019/NIH_Awards_2019.htm [Accessed 17 Apr 2020].
3 Wender RC. Family medicine in the research revolution. J Am Board Fam Med 2010;23:431-9.

4 Boyer EL. Scholarship Reconsidered: Priorities of the Professoriate. Princeton, N.J: Carnegie Foundation for the Advancement of Teaching, 1990.

5 ACGME program requirements for graduate medical education in family medicine. Available: https://www.acgme.org/Portals/0/ PFAssets/ProgramRequirements/120_FamilyMedicine_2019.pdf? ver=2019-06-13-073936-407 [Accessed 02 Apr 2020].

6 Grigsby RK. Five potential pitfalls for junior faculty at academic health centers. Acad Phys and Sci 2006.

7 Dyrbye LN, Varkey P, Boone SL, et al. Physician satisfaction and burnout at different career stages. Mayo Clin Proc 2013;88:1358-67.

8 Smith MA, Barry HC, Williamson J, et al. Factors related to publication success among faculty development fellowship graduates. Fam Med 2009;41:120-5.

9 AAFP. Is physician burnout on the decline. Available: https:// www.aafp.org/news/focus-on-physician-well-being/ 20190313burnoutdown.html [Accessed 16 Apr 2020].

10 Shanafelt TD, West CP, Sloan JA, et al. Career fit and burnout among academic faculty. Arch Intern Med 2009;169:990-5.

11 West CP, Dyrbye LN, Shanafelt TD. Physician burnout: contributors, consequences and solutions. J Intern Med 2018;283:516-29.

12 Lieff SJ. Perspective: the missing link in academic career planning and development: pursuit of meaningful and aligned work. Acad Med 2009;84:1383-8.

13 Schrager S. Transforming your presentation into a publication. Fam Med 2010;42:268-72.

14 Squire 2.0 guidelines. Available: http://squirestatement.org/index. $\mathrm{cfm}$ ?fuseaction=Page.ViewPage\&PagelD $=471$ [Accessed $16 \mathrm{Apr}$ 2020].

15 Glassick CE, Huber MT, Maeroff GI. Scholarship assessed: evaluation of the Professoriate. San Francisco: Jossey Bass, 1997.

16 Creswell JW, Creswell JD. Research design: qualitative, quantitative and mixed methods approaches. Sage Publications, 2017.

17 The Kirkpatrick model. Available: https://www.kirkpatrickpartners. com/Our-Philosophy/The-Kirkpatrick-Model [Accessed 16 Apr 2020].

18 Artino AR, Durning SJ, Sklar DP. Guidelines for reporting surveybased research submitted to academic medicine. Acad Med 2018;93:337-40.

19 Siwek J, Gourlay ML, Slawson DC, et al. How to write an evidencebased clinical review article. Am Fam Phys 2002;65:251-8.

202018 Journal citation reports (Clarivate analytics 2020).

21 Gottlieb M, Lotfipour S, Murphy L, et al. Scholarship in emergency medicine: a primer for junior academics Part I: writing and publishing. West J Emerg Med 2018;19:996-1002.

22 Reader S, Fornari A, Simon S, et al. Promoting faculty scholarship - an evaluation of a program for busy clinician-educators. Can Med Educ J 2015;6:e43-60. 